\title{
R. SPAEMANN: ¿ANTROPOLOGÍA O ÉTICA? LAGUNAS TEMÁTICAS Y NOÉTICAS DE UN CORRECTO PLANTEAMIENTO ANTROPOLÓGICO
}

\author{
Dr. Juan Fernando Sellés*
}

El presente trabajo estudia las claves de la antropología de Robert Spaemann. Siguiendo el pensamiento medieval, Spaemann distingue realmente entre persona y naturaleza humana, afirmando correctamente que la persona es relación abierta a la trascendencia divina. No obstante, defiende al mismo tiempo otras tesis, tales como que el tener naturaleza constituye el ser de la persona, afirmación con la que parece subordinar la antropología a la ética; o bien, que la persona es temporal, que es fin en sí, que se conoce por reflexión, postulados que no parecen del todo correctos.

Palabras clave: R. Spaemann, persona, naturaleza humana, apertura trascendente, tiempo, fin en sí, reflexión.

\section{R. SPAEMANN: ANTHROPOLOGY OR ETHICS? THEMATIC AND NOETIC GAPS FROM AN ACCURATE ANTHROPOLOGICAL APPROACH}

The present paper studies the keys of Robert Spaemann's anthropology. Following medieval thinking, Spaemann really distinguishes between person and human nature, properly affirming that the person is in open relation to divine transcendence. Nonetheless, other thesis are also defended such as that, having a nature constitutes a person's being, assertion that seems to subordinate anthropology to ethics; or that a person is temporary, that is an end in itself, that is known by reflection, premises that seem slightly wrong.

Keywords: R. Spaemann, person, human nature, transcendent opening, time, end in itself, reflection.

\footnotetext{
*Universidad de Navarra, Pamplona, España. Correo electrónico: jfselles@unav.es
} 



\section{Introducción}

En sus libros de corte más antropológicol ${ }^{1}$ Spaemann admite la distinción real entre persona y naturaleza humana ${ }^{2}$, la cual -como es sabido- se encuentra en la tradición medieval. En rigor, fue asumida por los cristianos desde el temprano Concilio de Calcedonia y posteriormente fue puesta de relieve por pensadores de la talla de Tomás de Aquino ${ }^{3}$. Spaemann entiende a la persona humana como "el titular de determinadas cualidades" la cual es más que ellas, es decir, la comprende como el sujeto o diferencia interna que tiene en su haber o poseer ciertas características comunes al género humano, pero que es irreductible a ellas. Lo que precede indica que persona denota distinción, mientras que "hombre es, en principio, el concepto de una especie biológica"s. Este planteamiento dual (aunque no "dualista") es correcto, pues toda realidad creada es compuesta, en concreto de acto y de potencia, o sea, de alguna dimensión superior o más perfecta y de alguna otra inferior o menos noble.

Lo anterior indica que Spaemann sigue, en antropología -aunque con otras palabrasla distinción tomista entre acto de ser y esencia, aunque referidas en este caso al hombre: "no definimos la identidad personal por sus rasgos cualitativos, aunque sean rasgos cualitativos de la especie hombre... Quiénes somos no se identifica evidentemente con lo que somos". Por eso añade que "los hombres se conducen respecto de lo que son (o de

1 Cfr. Spaemann, R., Personas. Acerca de la distinción entre 'algo' y 'alguien', Eunsa, Pamplona, 2000; Lo natural y lo racional, Instituto de Estudios de la Sociedad, Santiago de Chile, 2011; El rumor inmortal, Rialp, Madrid, 2010.

2 Cfr. por ejemplo, esta expresión: "las personas humanas existen teniendo una naturaleza". SpaEmanN, R., Personas, ed. cit., p. 182.

3 Tomás De Aquino, S. Theol., I, q. 29, a. 3 co.: "Persona significat id quod est perfectissimum in tota natura"; Ibid., I, q. 30, a. 4 co.: "hoc autem nomen persona non est impositum ad significandum individuum ex parte naturae, sed ad significandum rem subsistentem in tali naturae".

4 Spaemann, R., Personas, ed. cit., p. 28. En otro lugar escribe: "es característico de la persona, por una parte, el que su identidad numérica sea inequívoca, y, por otra parte, que no sea definible por ninguna determinación cualitativa". Ibid., p. 114. Con otra expresión: "la persona es siempre más que la suma de sus predicados". Ibid., p. 222.

5 Ibid., p. 30.

$6 \quad$ Ibid., p. 32. O dicho con otras expresiones suyas: "nadie es lisa y llanamente lo que es". Ibid., p. 34: "los hombres existen distinguiendo su ser de su modo determinado de ser, o sea, de una determinada 'naturaleza'. Los hombres no son simplemente su naturaleza, su naturaleza es algo que ellos tienen". Ibid., p. 49: "sea un hombre lo que sea, lo decisivo es que so no determina quién es ese hombre". Ibid., p. 57: "Las personas... no son esencias, sino que se comportan de cierto modo respecto de su esencia, la cual experimentan como contingente. Pero tampoco son el 'ser mismo' que se enajena en formas finitas de ser; no son el absoluto, puesto que solamente son en tanto que tienen un ser, una esencia finita, una naturaleza". Ibid., p. 86. Lo que precede recuerda a la distinción de Marcel entre ser y tener en el hombre. Cfr. Marcel, G., Etre et avoir, Philosophie européenne, AubierMontaigne, Paris, 1991, p. 48. En otros pasajes de Spaemann se lee: "mientras que la palabra hombre designa 
su clase o especie) de manera distinta a como se conducen normalmente los individuos de una clase respecto de ésta, los cuales se limitan a quedar incluidos dentro de ella"7, es decir, en los animales la especie es superior a los individuos y los engloba, mientras que cada persona humana ofrece un añadido distintivo a lo común de la especie humana ${ }^{8}$. Si se formulara literariamente esta tesis, se podría decir con el clásico castellano aquello de "visto un león, están vistos todos, y vista una oveja, todas; pero visto un hombre, no está visto sino uno, y aun ese no bien conocido".

\section{Su lectura histórica del concepto 'persona'}

Lo que precede indica que el término persona no es sinónimo de hombre, pues el primero describe una neurálgica realidad que sobrepasa con mucho a lo común de los hombres, asunto que es denotado por el segundo vocablo. Spaemann recuerda que el descubrimiento de la realidad personal es propio del cristianismo, lo cual es, sin duda, verdad: "lo que hoy denominamos 'persona', sin la teología cristiana, hubiera quedado sin nombrar, y no hubiera estado presente en el mundo"10, pues dicha teología llegó a desvelar la novedad y singularidad de la persona tras advertir que en la revelación cristiana se habla de un solo Dios con tres personas distintas; que Cristo es una única persona con dos naturalezas diversas; que cada uno de los ángeles difiere de los demás tanto por su persona como por su naturaleza, y que los primeros padres fueron dos personas (Adán y Eva) aunque disponían de una sola naturaleza, la humana (aunque cada uno la tuviese parcialmente: varón y mujer). Esta misma tesis referida a la historia se puede encontrar en otros pensadores contemporáneos ${ }^{11}$.

Para Spaemann, más que la singularidad, es la unicidad lo que caracteriza a la perso$\mathrm{na}^{12}$. Ahora bien, lo que determina que la persona sea única es, para este autor, su circuns-

una especie, una clase natural, definida por diferentes predicados de sus elementos, 'persona no alude a la clase, sino esencialmente al elemento de una clase, pro no en tanto que es elemento de esta clase, sino en tanto que es individuo". Spaemann, R., Personas, ed. cit., p. 50. Cfr. asimismo: Ibid., p. 54. Con todo, el término individuo, debido al significado que la filosofía contemporánea le ha atribuido, tampoco es adecuado para describir a la persona.

7 Spaemann, R., Personas, ed. cit., p. 37.

8 "Las personas no tienen el ser personal en común como los hombres tienen el ser hombres. 'Persona' no es un rasgo de la esencia, sino que designa aun individuum vagum, es decir, la respectiva singularidad de una vida individual". Ibid., p. 82. En otra obra suya escribe: "el sujeto personal trasciende a la sociedad, aunque tenga en ella su génesis". SPAEMAnN, R., El rumor inmortal, ed. cit., p. 102.

9 Gracián, G., El Criticón, Cátedra, Madrid, 1980, p. 225.

10 Spaemann, R., Personas, ed. cit., p. 38. En otra obra insiste: "el concepto filosófico de persona no es comprensible sin la teología cristiana... La noción de persona surge directamente del dogma trinitario". SPaEmann, R., El rumor inmortal, ed. cit., p. 84. Cfr. asimismo al respecto la entrevista a Robert Spaemann en: http://www. bioética.com.mx, donde el autor declara que "las discusiones trinitarias y cristológicas permitieron desarrollar un concepto de persona que permitiera distinguir entre persona y naturaleza, o entre persona y esencia".

11 Cfr. por ejemplo, Polo, L., La originalidad de la concepción cristiana de la existencia, Eunsa, Pamplona, $2^{\mathrm{a}}$ ed., 2012; Zubiri, X., Sobre el sentimiento y la volición, Alianza, Madrid, 1992, p. 372; Palacios, L. E., El concepto de persona, Rialp, Madrid, 1989; Martínez Poncell, J., Metafísica de la persona, PPU, Barcelona, 1992; Forment, E., Ser persona, U. de Barcelona, Barcelona, 1983; LomBo, J. A., La persona en Tomás de Aquino, Apollinare Studi, Roma, 2001.

12 "Lo que hace que la persona sea persona no es su singularidad, si no el ser única". Spaemann, R., Personas, ed. 
cripción espacio-temporal ${ }^{13}$. Con todo, es claro que tal circunscripción no puede atribuirse a todas las personas, sino sólo a las humanas, y a éstas, sólo mientras poseen la corporeidad. En cualquier caso, la radicalidad personal -añade el filósofo alemán- estuvo precedida en las Sagradas Escrituras por el término corazón, de manera que "el corazón, según este modo de entenderlo, no es naturaleza" ${ }^{\prime 14}$, extremo que también es correcto, pues es sinónimo de 'persona'. Indica asimismo que "el corazón es fundamento sin fundamento"15, lo que equivale a que no lo está comprendiendo como una 'sustancia' o como un 'acto de ser necesario', sino como una realidad libre, y esta tesis es asimismo certera. Añade que, posteriormente, en la era cristiana, los primeros teólogos designaron el término persona como hipóstasis, es decir, como equivalente a ser que existe independientemente. Este punto se puede advertir, por en ejemplo en San Juan Damasceno ${ }^{16}$.

Es correcta asimismo su crítica a la definición boeciana de persona, la cual-como es sabido- llegaría a ser célebre y a imponerse en el panorama filosófico medieval: "mientras que en el marco de la doctrina de la Trinidad substantia y essentia son sinónimas, y se trata de una 'substancia divina' en tres hypostasis o personas, Boecio emplea 'substantia' con el sentido de 'hypostasis', frente a esencia, a la que denomina 'natura"'17. Por esto Spaemann acepta la crítica de Ricardo de San Víctor al último romano, pues para el victorino "persona... no puede ser substancia, sino titular de una substancia"18. Por su parte, usando del lenguaje actual, Spaemann gusta llamar a la persona como alguien, mientras que a aquello de lo que ésta se distingue lo denomina $\operatorname{algo}{ }^{19}$.

En algunos pasajes Spaemann parece admitir que la persona humana sea superior a la naturaleza humana, pues entiende la primera como directora de la segunda, hasta el punto de decir que el hombre no es algo fijo, sustante o estable, sino variable: "el hombre puede merecer o ser hombre o ser indigno de serlo" ${ }^{20}$. Debido a dicha superioridad, cada persona humana puede perfeccionar su naturaleza, o también, denigrarla y atentar contra

cit., p. 163. En otro capítulo distingue entre hombre y persona teniendo en cuen-ta esta unicidad, aunque las expresiones que usa para exponerla no sean del todo apropiadas: "Los hombres son más o menos semejantes como hombres. Como personas no son semejantes, sino iguales, y lo son en el sentido de que cada una es única y su dignidad es inconmensurable”. Ibid., p. 181. Sin embargo, la igualdad no sirve para tal descripción porque es exclusivamente mental, ya que en la realidad no existen dos cosas iguales.

13 "Ser único no es una mera consecuencia de la singularidad, sino algo que sólo se define indexi-calmente por el lugar espacio-temporal que ocupa". Ibid., p. 163.

14 Ibid., p. 41. En otro capítulo afirma que "la no identidad con la propia naturaleza nos obliga a llamar a los hombres "personas". Ibid., p. 93. En otro lugar se lee esta sentencia: "Los seres humanos no son su naturaleza". Ibid., p. 96. Y más adelante añade: "El hombre tiene naturaleza. No es la naturaleza la que lo tiene a él". Ibid., p. 105; "Como seres que tenemos una naturaleza, disponemos de la nuestra propia y de la naturaleza en su conjunto". Ibid., p. 106.

15 Ibid.

16 Cfr. San Juan Damasceno, De fide ortodoxa, III (PG MG, 44, 985-988).

17 Spaemann, R., Personas, ed. cit., p. 47.

18 Ibid. p. 48. "Persona designa una proprietas qui non convenit nisi uni soli... Existens per se solum juxta singularem quamdam rationalis existentiae modum". Ibid.

19 "La persona es alguien, no algo, no un mero caso de una esencia indiferente frente a él". Ibid. 48. La misma atribución de alguien, a distinción de algo, la refiere a Dios en su obra El rumor inmortal, ed. cit., p. 19.

20 Spaemann, R., Personas, ed. cit., p. 29. 
ella. En otros pasajes, en cambio, tal superioridad no parece tan clara, pues para evitar que la distinción denote contraposición tiene a fusionarlas: "la contraposición entre naturaleza y persona olvida que la persona es en sí mismo una naturaleza en la que se representa la persona, en la que la persona se puede contemplar y tocar" ${ }^{21}$. Obviamente no se trata de contraponer ambas dimensiones humanas, sino de hacer ver que las distinciones reales en lo creado, por tanto también en el hombre, no pueden ser sino jerárquicas.

\section{Sus tesis antropológicas centrales}

A lo anterior Spaemann agrega una certera averiguación, a saber, que la persona dice relación personal: "la diferencia que las personas mantienen con su naturaleza, con su esencia, está inmediatamente relacionada con el hecho de que una persona entendida de ese modo sólo se puede pensar en relación con otras personas, o sea en plural"22, o brevemente expuesto: "las personas son mutuamente personas. Sólo hay personas en plural"23. Esta es la tesis fuerte -y certera- del autor y la que da sentido al título de su obra más antropológica: Personas.

Tenemos naturaleza, pero, como personas, no la $\operatorname{somos}^{24}$. Sin embargo, Spaemann afirma-salvo en un pasaje $\mathrm{e}^{25}$ - que ese tener es nuestro $\operatorname{ser}^{26}$, lo cual no es coherente, pues el tener es propio de la esencia humana, no del acto de ser personal. En efecto, el ser personal

21 Spaemann, R.,Felicidad y benevolencia, ed. cit., p. 248.

22 Spaemann, R., Personas, ed. cit., p. 46. En otro lugar añade: "la identificación de sí mismo no es posible de forma solipsista, sino que incluye necesariamente... la existencia de otros y un dato posible para ellos". Ibid., p. 54; "es propio del concepto de persona... superar desde el principio, el solipsismo metódico". Ibid., p. 55; "cada persona mantiene a priori con las demás una relación". Ibid., p. 56; "el solipsismo es incompatible con el concepto de persona. Una única persona en el mundoes algo que ni se puede pensar". Ibid., p. 57; "Sólo en plural hay personas... Las personas son seres para los que otra identidad deviene real, y cuya identidad deviene real para los otros". Ibid., p. 89; "Si no soy un 'tú', tampoco puedo ser un 'yo"'. Ibid., p. 90. En otro escrito indica que esa relación personal del hombre es con el ser divino: "la relación del hombre con el Absoluto compromete al hombre en lo más profundo. Define su identidad de modo aún más central que la pertenencia a una nación". Spaemann, R.,, El rumor inmortal, ed. cit., p. 131.

23 Ibid., p. 137. Más adelante reitera: "Sólo en plural hay personas". Ibid., p. 223.

24 "La persona no es sencillamente su naturaleza, sino que la tiene". Ibid., p. 196.

25 "Éste (un hombre) tampoco es idéntico a todo lo que tiene". Ibid., p. 184.

26 Spaemann reitera en abundancia esta tesis. He aquí algunos pasajes: "Los hombres no son simplemente su naturaleza, su naturaleza es algo que ellos tienen. Y este ser es su tener". Ibid., p. 49. "Este tener es nuestro ser, disponemos de nosotros mismos". Ibid., p. 106; "Ser persona significa tener una naturaleza y la correspondiente relación consigo". Ibid., p. 108. "Su ser no es otra cosa que tener una naturaleza semejante y disponer de ella". Ibid., p. 115. "Su ser es tener una naturaleza". Ibid., p. 116. "Su ser es tener su vida y no una entidad más allá de la vida". Ibid., p. 123. "Tener la vida es el ser de la persona". Ibid., p. 127. "Los hombres tienen su vida, pero la tienen como receptores que no han sido preguntados, pues son exclusivamente en tanto que han recibido la vida". Ibid., p. 128. "El ser de la persona es tener su vida". Ibid., p. 131. "Las personas son por tener, como naturaleza, lo que son". Ibid., p. 137. "El ser de las personas es tener una naturaleza". Ibid., p. 138. "Siendo el ser de la persona un tener". Ibid., p. 157. "el 'tener', que constituye el ser de la persona". Ibid., p. 158. "Si el ser de la persona es tener, la persona sólo puede ser reconocida reconociendo lo que tiene, su vida, su cuerpo, su fama, su propiedad y libertad de movimiento que reclama para su autodespliegue". Ibid., $p$. 185. "Ser persona significa aquella íntima estructura en la que un hombre posee su naturaleza". Ibid., p. 186. "Es precisamente esto lo que distingue a la persona, que se relaciona con su realidad natural en el modo de tenerla". Ibid., p. 216. "El ser de la persona consiste en tener una naturaleza". Ibid., p. 218. 
no dispone de una esencia humana, sino que dispone según ella. Si tener una naturaleza fuese el carácter distintivo de la persona humana, el fin de la persona sería el tener, no el ser, es decir, consistiría en ocuparse de la esencia humana en orden a su crecimiento, como el autor afirma ${ }^{27}$. Según esto el fin del hombre sería la ética, y una persona sería más persona en la medida en que fuese más ética, como él sostiene ${ }^{28}$. Sin embargo, la ética deriva de y es para la antropología de la intimidad, de modo parejo a como "el obrar sigue al ser", no a la inversa, porque el obrar es segundo y está en función del ser, no al revés. La ética mejora a la esencia humana, en concreto a la razón con hábitos intelectuales y a la voluntad con virtudes, pero no perfecciona al acto de ser personal, porque ni los hábitos ni las virtudes radican en él, sino en las potencias inmateriales humanas (inteligencia y voluntad respectivamente), y es claro que nadie se reduce a su inteligencia y a su voluntad por muy perfeccionadas que éstas se hallen.

Por esto, el destino de la persona humana no puede ser su obrar, sino una persona distinta que la acepte enteramente y la pueda hacer culminar felicitariamente; el destinatario de una persona humana no es, por tanto, la naturaleza humana, la cual no es persona y es inferior a ella ${ }^{29}$. En suma, la esencia humana no es el fin de la persona (el fin de la persona no es la adquisición de hábitos intelectuales y virtudes en la voluntad), porque estas perfecciones son teneres, no el ser. Si lo distintivo de la persona fuese el tener, la persona no sería superior a lo tenido, por ejemplo, a su vida; pero es claro que lo somos, porque podemos entregarla por motivos personales. Spaemann sostiene que no se da tal hegemonía ${ }^{30}$. Sin embargo, frente a este postulado, hay que sostener que lo que caracteriza a la persona humana (y a toda persona) no es el tener, sino justamente el ser.

Por otra parte, acierta Spaemann al caracterizar a la intimidad humana con el rasgo de su apertura a la trascendencia divina, aunque ésta no parece entenderla como constitutiva, sino sólo como posible ${ }^{31}$.

En suma, persona y naturaleza conforman la dualidad con que Spaemann describe al hombre. Acepta la distinción real entre persona y naturaleza humana, pero explica la persona en orden a la naturaleza, lo superior en referencia a lo inferior: "las personas no son inmediatamente su naturaleza. Las personas tienen que conseguir de continuo tener una naturaleza"32. Pero, si bien se mira, esta pretensión es inane para la persona creada,

27 "Si ser persona es tener una naturaleza, la integridad de esta naturaleza es esencial para la persona". Ibid., p. 106.

28 "El hombre aprende a descubrir el propio error de conciencia como defecto ético, o sea, como obstáculo en el camino que nos hace ser persona". Ibid., p. 173.

29 Nótese además que si lo característico de una persona fuera tener una esencia, la noción de persona no sería atribuible a Dios, porque las personas divinas, en rigor, no tienen una naturaleza divina, sino que la son, pues en Dios no cabe distinción real entre acto de ser y esencia.

30 "Responsabilidad por la propia vida supone que las personas tienen su vida, aunque no en el sentido de que sean una entidad propia más allá de ese tener". Ibid., p. 164.

31 "El que la dimensión religiosa forme parte del ámbito de la posibilidad humana es constitutivo del carácter personal del hombre". Ibid., p. 105. En una entrevista a Spaemann éste afirma al res-pecto: "lo que el hombre piensa de sí mismo depende de que exista Dios o no". Cfr. http://www.bioetica.com.mx

32 Spaemann, R., Personas, ed. cit., p. 116. 
porque el sentido de lo superior, del acto de ser personal, no se puede encontrar ni recabar en el desarrollo de lo inferior, de la naturaleza humana, sino en lo superior a la propia persona, o sea, en la propia y progresiva apertura al ser divino. De lo contrario, el fin de una persona humana no sería Dios, sino las perfecciones humanas de la naturaleza humana, o sea, lo humano de la humanidad. Pero, si como se ha adelantado -y como el mismo autor admite-, una sola persona es superior a lo común del género humano, su norte o sentido no puede radicar en dicha naturaleza.

Defiende Spaemann la precedente tesis porque piensa que su contraria con llevaría a un dualismo ${ }^{33}$, a una pretensión ilegítima de desvincular la persona de su naturaleza, de lo cual derivaría una instrumentalización de la naturaleza humana y una imposibilidad de acceso a Dios ${ }^{34}$. Pero hay que soslayar este temor, pues el acto de ser creado no se da nunca sin su esencia (aunque se pierda la naturaleza corpórea con la muerte, el acto de ser personal sigue activando el yo, la inteligencia y la voluntad, los cuales conforman la esencia humana). La persona humana no está llamada a desvincularse de su naturaleza humana, ya que constitutiva y naturalmente la activa y perfecciona. Por lo demás, si bien la naturaleza humana está abierta a Dios, (especialmente a través de la voluntad y de la inteligencia), en mayor medida lo está la persona humana, pues en este caso la apertura es precisamente personal. En síntesis, el destino de la persona humana no está en activar y perfeccionar la naturaleza humana, pues de ser así su destino no sería personal.

Dejando a salvo la tesis precedente, hay que hacer valer del pensador alemán su gran verdad acerca de la distinción real entre persona y naturaleza, a la que añade otra no pequeña, a saber, que sólo la naturaleza humana, no la persona, es sexuada: "el ser personal reside en tener una naturaleza humana, pero en tener una naturaleza masculina o femenina, es decir, una naturaleza que incluye la ordenación a la persona del otro sexo. La persona como tal no es sexual. Sólo está referida a priori a otra persona" ${ }^{35}$. Frente a esta tesis algunos autores recientes han propuesto que la distinción sexual afecta asimismo al núcleo personal ${ }^{36}$. Pero como he tenido oportunidad de fundamentar en otro lugar ${ }^{37}$, considero que tal supuesto no es necesario, sencillamente porque las distinciones entre las personas no son tipológicas o comunes, ya que no existen dos personas iguales (ni entre

33 "Hoy en día se ha convertido en un lugar común, incluso entre teólogos católicos, oponer el concepto de persona al concepto de naturaleza y cuestionar, por ejemplo, la relevancia moral del concepto de naturaleza. Ésta es sólo una de las formas en que aparece actualmente el mencionado dualismo". SPAEMANN, R., Lo natural y lo racional, ed. cit., p. 23. Dicho temor al dualismo lo comparte la autora del artículo "Naturaleza y dignidad personal, desde el pensamiento de R. Spaemann", disponible en: http://mercaba.org/Filosofia/Antropologia

34 "La tendencia actual de la teología moral a desvincular el concepto de persona del de 'naturale-za humana', así como a entender ésta en relación al ser-persona en términos objetivos e instrumentalizables ha de verse en la línea del espiritualismo... Si el ser persona y la naturaleza humana se separan entre sí por tal abismo ontológico, entonces no resulta plausible concebir la relación que el hombre tiene con Dios -es decir, el más profundo núcleo de su ser personal-". SPaEmann, R., El rumor inmortal, ed. cit., p. 176.

35 Spaemann, R., Personas, ed. cit., p. 219.

36 Cfr. Castilla, B., "En torno a la díada trascendental", Anuario Filosófico, XXIX/2 (1996), pp. 397-414; Persona femenina, persona masculina, Rialp, Madrid, 1996; YePEs, R., Fundamentos de antropología, Eunsa, Pamplona, 1996, p. 269; Ruiz Retegui, A., "La sexualidad humana”, Deontología biológica, Universidad de Navarra, Pamplona, 1987, p. 265. 
varones, ni entre mujeres, ni entre ángeles y personas divinas), pues cada persona, por ser novedad radical, es distinta.

\section{Una visión totalizante}

El intento de Spaemann de fusionar la persona con la naturaleza parece res-ponder a una mentalidad totalizante, es decir, a una visión de compendio o suma entre ambas dimensiones humanas, de tal manera que no puede entender la primera sin la segunda, hasta el punto de afirmar que "la persona no persiste cuando el hombre desaparece" 38 , o también que "el cuerpo humano es el hombre mismo" 39 . Sin embargo, la persona es tanto o más persona con o sin cuerpo, pues el cuerpo no es la persona; la persona humana dispone de cuerpo pero no es cuerpo. Tesis afines a esta mentalidad se pueden encontrar en otros pensadores del s. XX, por ejemplo, en algunos escritos de Edith Stein, Max Scheler, Gabriel Marcel, Martín Buber, Paul Ricoeur, Xavier Zubiri, etc.

Pero la visión totalizante es injustificable ${ }^{40}$ por varias razones: por una parte, porque es contraria a la realidad, es decir, a la composición de acto y potencia en lo creado (recuérdese la tesis aristotélica), pues es claro que el acto se puede dar y comprender al margen de las potencias y que el fin del acto no es el desarrollo de las potencias. Por otra parte, tal hipótesis no acaba de casar con la revelación cristiana, pues es absurdo decir que tras la pérdida del cuerpo con la muerte no quepa hablar de persona ${ }^{41}$. La persona humana no es cuerpo, sino que dispone de cuerpo ${ }^{42}$ (además, no todas las personas tienen cuerpo, y no por ello dejan de ser personas).

En virtud de la mentalidad coleccionista indicada, para Spaemann la muerte no significa no tener, sino no ser $^{43}$. Pero obviamente no puede ser así, pues con la muerte se pierde el cuerpo, la naturaleza corpórea humana, pero no el acto de ser personal. Tampoco se disipa la esencia humana, si por esta se entiende -como se ha adelantado- la inteligencia, la voluntad y el yo. Si el ser del hombre fuese tener su vida -como afirma Spaemann ${ }^{44}$-, tras la pérdida de la vida en el momento de la muerte la persona no sería. Pero no es así,

37 Cfr. mi trabajo: Antropología para inconformes, Madrid, Rialp, $3^{\mathrm{a}}$ ed., 2012, cap. 8: 'Varón y mujer'.

38 Spaemann, R., Personas, ed. cit., p. 116.

39 Spaemann, R., Lo natural y lo racional, ed. cit., p. 117. en otra obra suya sostiene la misma tesis: "el cuerpo humano es el hombre mismo". Felicidad y benevolencia, ed. cit., p. 248.

40 Cfr. mi trabajo: "La aporía de las antropologías 'totalizantes' como pregunta a los teólogos", Salmanticenses, LVII/2 (2010), pp. 273-297.

41 Spaemann, R., Personas, ed. cit., p.116.

42 Para Spaemann, "la corporeidad es el medio gracias al cual la persona es ser para los demás", Personas, ed. cit., p. 91, lo cual es correcto. Pero añade que "se trata de algo que le pertenece (a la persona) esencialmente". Ibid., lo cual no es correcto, no sólo porque no toda persona posee cuerpo (las angélicas y divinas), sino porque el cuerpo humano no pertenece a la persona o acto de ser personal humano, sino a la naturaleza humana. En otro pasaje escribe: "el ser de la persona es tener un cuerpo animado". Ibid., p. 157.

43 "No podemos evitar saber que alguna vez no seremos, sino que habremos sido". Ibid., p. 121.

44 "Experimentamos lo que es la vida experimentando la vida como nuestro ser, es decir, como el ser de las personas". Ibid., p. 157. 
porque la persona es realmente distinta de su vida biológica y biográfica. La persona es espíritu, y éste no muere con la muerte del cuerpo. Al espíritu le puede afectar otro tipo de muerte, la espiritual, pero ésta ni denota no tener, ni depende del no tener corpóreo, sino que significa no ser, sencillamente porque la persona no se acepta libremente ser quien es y está llamada a ser. Spaemann defiende la aludida tesis porque considera -con Aristóteles- que "la vida es el ser de los vivientes". Sin embargo, la vida no es el acto de ser de los vivientes, ni siquiera su esencia, sino su naturaleza corpórea (téngase en cuenta que el Estagirita no descubrió la distinción real entre acto de ser y esencia). En el hombre hay que distinguir entre "vida natural" y "vida personal" y subordinar la primera a la segunda, no a la inversa.

Por otra parte, Spaemann no establece distinciones entre espíritu, alma y yo, sino que usa esos términos como sinónimos ${ }^{45}$. Sin embargo, en la tradición bíblica y medieval se da una distinción entre los dos primeros, pues se dice que el espíritu mira a Dios, mientras que el alma mira a vivificar el cuerpo y a las potencias inmateriales ${ }^{46}$. Por su parte, en el pensamiento reciente se distingue entre el yo o el alma y la persona o el espíritu ${ }^{47}$. Por eso se puede decir con sentido que conozco mi yo, pero que, en rigor, no sé quién soy como persona, lo cual indica que el yo forma parte de la esencia humana, mientras que la persona es el acto de ser personal, el cual, aunque en cierto modo es alcanzado por mi conocer, desborda dicho conocimiento. El yo, en cambio, se conoce sin dificultad (incluso la psicología hace tipologías de yoes); no obstante, la persona supera al conocer que lo alcanza, lo cual indica que no la puede comprender. Spaemann admite que el hombre tiene un alma, pero identifica ésta con el ser del hombre ${ }^{48}$. De modo que estamos de nuevo ante la equivocidad entre ser y tener. Por lo demás, en algún escrito trata de la inmortalidad del alma como de un postulado ${ }^{49}$.

\section{La cuestión del tiempo humano}

En algún texto Spaemann da a entender que el pasado sea superior al futuro en el hombre, porque describe a la persona en orden a tener la naturaleza humana ${ }^{50}$, es decir, a sacar partido a ésta a lo largo de la historia. Esta visión es similar a la de quien considera que la clave del hombre es haber tenido una vida lograda ${ }^{51}$. Lo que subyace bajo esta mentalidad

45 Cfr. Ibid., p. 151 ss.

46 "Magnificat anima mea Dominum, et exultavit spiritus meus in Deo salvatore meo", Lc., I, 46-47; "Vivus est enim Dei sermo et eficax et penetrabilior omni gladio ancipiti et pertingens usque ad divisiones animae ac spiritus". Hb., IV, 12; "Benedicite, spiritus et anima iustorum, Domino; laudate et superexaltate eum in saecula", Dn., III, 86.

47 Cfr. Polo, L., Antropología trascendental, I-II, Eunsa, Pamplona, 2000-2003.

48 "Los hombres tienen un alma. Pueden, como ocurre con frecuencia en textos arcaicos, 'hablar con su alma'. Quien habla en estos casos no es una entidad más allá del cuerpo y el alma, sino el hombre mismo". SPAEMANN, R., Personas, ed. cit., p. 159.

49 Cfr. Ibid., p. 158 ss.

50 Cfr. Ibid., p. 116.

51 También Spaemann lo considera así en Felicidad y benevolencia, Rialp, Madrid, 1989, p. 33 ss. 
es, en rigor, que la ética es superior a la antropología de la intimidad, o también, que no acaba de perfilar la distinción entre ambas. Pero es claro que en el hombre el futuro es siempre superior al pasa-do, pues es un ser de proyectos (que subordina todo su pasado y presente a ellos), porque él, como persona, (y mientras vive en la presente situación) es un proyecto siempre inconcluso. Es más, porque lo es en su acto de ser, es asimismo un proyecto inacabado en su esencia y naturaleza.

De otro modo: el sentido de una persona humana no radica en su biografía pasada, ni en su actual estado, sino en el ser que está llamada a ser. El llegar ser o cumplir esa vocación, si libremente desea, es siempre en el hombre un sentido superior a lo que ha sido y es. Sin tal peso del futuro no cabría crecimiento (en el acto de ser personal y en la esencia humana), y tampoco elevación divina. Además, como Spaemann admite que el "tener supone temporalidad" ${ }^{2}$, y sostiene que "las personas son por tener" ${ }^{53}$, en rigor acepta que las personas son tiempo. Con lo que, por una parte, no se acaba de ver cómo su antropología supera las precedentes visiones temporalistas del hombre (Marx, Nietzsche, Freud, Heidegger, etc.) y, por otra, cómo con ése esquema puede atribuir el nombre de persona a las personas divinas.

Con todo, también admite Spaemann que "la persona es una promesa"54. Ahora bien, la promesa siempre dice relación al futuro, o al menos, como él sostiene, está por encima del tiempo físico: "cuando prometen, los hombres se elevan por encima de su inmersión natural en la corriente del tiempo" 55 . Otro gran acierto suyo estriba en defender que mientras se vive no desaparece nunca la persona: "mientras viva, nadie puede, sea cual sea u comportamiento, desaparecer completa y definitivamente como persona, convertirse en algo impersonal y hacer que desaparezca la diferencia entre su identidad personal y su esencia"56. Esta tesis abre la puerta a afirmar que tras la vida presente sí se puede perder completa y definitivamente la realidad personal. Pero sobre este punto Spaemann no se pronuncia.

\section{Fin en sí y dignidad}

Spaemann acepta - con Kant- que la persona es fin en si $^{57}$ (afirma incluso que es serpara-si $\left.i^{58}\right)$. Pero, la noción de fin, que sirve bien para explicar las potencias superiores humanas (inteligencia y voluntad), no es conveniente para describir a la persona, porque,

\footnotetext{
2 Spaemann, R., Personas, ed. cit., p. 137.

3 Ibid.

54 Ibid., p. 215. "El fenómeno de la promesa arroja una luz especialmente clara sobre lo que llamamos "persona"”. Ibid. "unimos inmediatamente el contenido de la promesa con la promesa que somos en tanto que personas. Para romper aquella tenemos que romper ésta. Si lo hago desaparezco como persona”. Ibid., p. 217.

55 Ibid., p. 215.

56 Ibid., p. 225

57 Cfr. Ibid., p. 131. Cfr. asimismo: Spaemann, R., Lo natural y lo racional, ed. cit., p. 100.

58 Cfr.Spaemann, R., Lo natural y lo racional, ed. cit., p. 101.
} 
en rigor, ésta no es fin, puesto que es coexistente o constitutiva relación personal con otra persona, sobre todo, con su Creador. Con esto no se quiere decir que se pueda concebir a la persona humana como medio y tratarla como tal. Lo que se quiere indicar es lo señalado, a saber, que las nociones de medio y fin son inferiores a realidad personal. Desde luego que -como observa Spaemann- la persona es superior a su contexto, y que no se la puede medir en orden a él. Pero eso no equivale a que sea fin, y menos último.

Otras veces atribuye a la persona humana el término dignidad". Para él, "la dignidad humana sólo corresponde a quienes poseen de hecho aquella propiedad por la cual nos reconocemos unos a otros la racionalidad y la capacidad de auto-determinación moral" ${ }^{60}$. Si ahora establecemos la equivalencia entre persona y dignidad, y notamos que Spaemann describe la persona en términos de racionalidad ${ }^{61}$ y moralidad, esto equivale a describir la dignidad personal apelando a las potencias humanas superiores: la inteligencia y la voluntad. Además, a veces vincula la conciencia a la persona humana, no a la naturaleza humana, pues afirma que "tener conciencia es el signo más terminante de la persona"62, y también que "la conciencia representa la dignidad de la persona" ${ }^{3}$. Añádase que, en alguna ocasión, vincula la conciencia a la razón práctica ${ }^{64}$, según lo cual lo distintivo de la persona sería el uso práctico de su razón. Como se puede advertir lo que precede no es enteramente adecuado, porque implica atribuir tal dignidad, más que a la persona, a su naturaleza o esencia.

Con todo, otras veces Spaemann indica que, para valorar que uno es persona humana, basta saber si pertenece, por su origen a la especie 'homo sapiens ${ }^{65}$, no en si tiene en acto autoconciencia y racionalidad, sino en que posee la capacidad de alcanzarlas ${ }^{66}$. Para una

59 "el concepto de dignidad se refiere a la propiedad de un ser que no es sólo 'fin en sí mismo para sí', sino 'fin en sí mismo por antonomasia”.' Spaemann, R., Lo natural y lo racional, ed. cit., p. 69.

60 Spaemann, R., Lo natural y lo racional, ed. cit., p. 73.

61 "El que debamos reconocer como personas a todos los pertenecientes a nuestra especie pone de manifiesto que tenemos que considerar la racionalidad como nota natural de la especie, de cuyos privilegios participa cada uno simplemente porque participa de la naturaleza humana". Lo natural y lo racional, ed. cit., p. 100. Y más adelante Spaemann añade: "la persona, el ser racional, capaz de libre autodeterminación, potencialmente moral". Ibid., p. 118. Con todo, no es conveniente decir que uno es persona porque participe de la racionalidad -característica común de la especie hombre-, sino que es más bien la racionalidad la que depende de la persona, no a la inversa; lo inferior, la razón, depende de lo superior, la persona, la potencia del acto, la esencia del acto de ser.

62 Spaemann R., Personas, ed. cit., p. 165. En otro lugar escribe: "es un rasgo esencial de la persona no ser sólo conciencia, sino tener una naturaleza. Las personas no son exclusivamente sujetos conscientes, sino sujetos conscientes tales que, simultáneamente, se conocen como cosas naturales en el mundo, aunque tienen que saber necesariamente cuál es su naturaleza". Ibid., p. 112. Sin embargo, la persona ni se conoce como una cosa natural en el mundo, puesto que no es ninguna cosa natural, sino una realidad personal, ni tiene que saber necesariamente cuál es su naturaleza, pues ya se ha indicado que la naturaleza humana ni es persona ni es el fin de la persona. Por ejemplo, el cuerpo humano pertenece a la naturaleza humana, pero no es la persona, sino de la persona. Por eso cabe que se dé un cuerpo humano sin persona humana: un cadáver.

63 Ibid., p. 168. en otro lugar añade: "En ella (conciencia) se expresa, como en ninguna cosa, lo que distingue a la persona". Ibid., p. 173.

64 "La conciencia, como voz de la razón práctica". Ibid., p. 171.

65 Cfr. por ejemplo: Spaemann R., Lo natural y lo racional, ed. cit., p. 119.

66 Cfr. En http://eresdelosquepiensan.org aparece en castellano el artículo de Spaemann: ‘Son todos los hombres personas?', que es traducción de “¿Sind alle Menschen Personein?”, publicado en Communio, (1990), pp. 
estudiosa de este pensador alemán, "nuestro ser personas no tiene realidad alguna fuera de nuestro ser seres naturales. Nuestra especialísima dignidad no es una nota al margen de nuestra naturaleza... Sólo volviendo a vernos como naturaleza resulta operativo el concepto de dignidad humana" ${ }^{97}$. Pero estas afirmaciones parecen defender, más que una unión, una fusión o macla entre persona y naturaleza. No se trata, obviamente, de contraponer la persona a la naturaleza humana, o de usar la inferior como mero instrumento, sino de distinguirlas, pero viendo cómo la inferior está diseñada para servir a la superior y como la superior puede favorecer a la inferior.

Ya se ha indicado que la persona humana no se reduce a la naturaleza humana, ni puede ser comprendida teniendo en cuenta sólo a ésta. Según esto, la conciencia moral no puede ser lo distintivo de la persona humana, aunque tal conciencia sea superior a la conciencia que ofrece la razón práctica, pues la conciencia moral es inferior a la persona, ya que no es la persona, sino de ella, y no está referida al ser de la persona, sino a aquello de lo que ésta dispone. En efecto, la conciencia moral es ese conocimiento del estado de todas nuestras potencias humanas (incluidas la inteligencia y la voluntad). Aunque tal conciencia es un conocer humano muy alto, no forma parte del acto de ser o persona, y no conoce a la persona, sino que es de la esencia humana; más aún, es la cúspide de ella. A tal conciencia los pensadores medievales la denominaron sindéresis, y la caracterizaron como un hábito innato; y es claro que un hábito indica tener (habere), no $s^{6}{ }^{68}$. De manera que un hombre es persona aunque no haya ejercido tal hábito. En suma, hay que tomarse en serio que el acto de ser personal es realmente distinto de la esencia humana.

La conciencia a la que Spaemann alude no puede ser lo distintivo de la persona, porque es obvio -como él mismo advierte- que hay muchos estados de la persona humana en que no es consciente de sus actos y potencias (por ejemplo, en el seno materno, durante el sueño, con enfermedades graves, lesiones, en fases terminales, etc.), y es manifiesto que en esas situaciones no se deja de ser persona, tanto o más digna que en su estado consciente. Si a ello se objeta que en esos estados no tiene conciencia, pero posee la capacidad de tenerla, hay que responder, que aunque no tuviera tal capacidad durante toda la vida no por ello dejaría de ser persona, porque tal conciencia hay que predicarla del tener de la persona, no de su ser.

108-114. En dicha página web Spaemann identifica persona y personalidad: "la personalidad es, por tanto, el elemento constitutivo del ser humano". Pero no es así, porque es claro que existen muchas personas sin personalidad definida (por ejemplo las que viven en el seno materno), que otras la tienen alterada (las personas con enfermedades psíquicas). En rigor, no advierte que persona es el acto de ser humano, mientras que la personalidad forma parte de la esencia humana.

67 González, A. M., Naturaleza y dignidad, Eunsa, Pamplona, 1996, p. 229.

68 La sindéresis no es la única conciencia de nuestro tener, aunque sí la superior. Inferior a ella son los hábitos de la razón, tanto los de la razón práctica como los de la razón teórica, los cuales son la conciencia de nuestros actos racionales en dichos usos. Inferior a éstas es la conciencia sensible, sensorio común o percepción. En cualquier caso, ninguna de estas conciencias es conciencia del acto de ser personal, es decir, de que uno es persona. 
De otro modo: la conciencia a la que el autor alude se requiere para funda-mentar la ética, es decir, para responsabilizarnos de nuestras potencias y de sus actos, pero no para explorar nuestra intimidad, es decir, no es solvente para desvelar la antropología trascendenta $l^{69}$. Es correcto indicar que "el carácter absoluto de la voz de la conciencia se debe al carácter absoluto de la persona" ${ }^{70}$, si por persona se entiende el acto de ser personal, pero, a la par, hay que añadir que la persona no es tal conciencia, sino que es superior a ella. Por otra parte, de la persona, más que decir que tiene carácter absoluto -en el sentido de absuelto-, es mejor indicar que lo tiene vinculado. Con todo, se trata de una vinculación enteramente libre, no necesaria, porque la libertad es personal.

\section{Reflexión y aceptación}

Abordemos a partir de aquí la dificultad respecto del método noético para conocer la persona. En cuanto a tal conocimiento, Spaemann indica que a la persona humana le resulta sencillo saber que existe, pero en extremo difícil saber quién es ${ }^{71}$, lo cual es manifiesto. Tal conocimiento se alcanza -indica unas veces- con el método de la reflexión 72. Otras añade que "lo que el hombre es se nos ofrece intuitiva y conceptualmente, pero quién es ese hombre nos resulta accesible exclusivamente en el acto de aceptación de lo que se sustrae definitivamente a nuestras posibilidades de alcanzarlo" 73 . Sin embargo, y por una parte, la "teoría de la reflexión" es incoherente ${ }^{74}$. Además -como el mismo autor advierte- "el equilibrio entre trascendencia y reflexión es inestable" 75 , pues si la reflexión fuera completa y la persona humana pudiese dotarse de entero sentido a sí misma, es claro que Dios estaría de más. Por otra, la aceptación es propia del amor personal, y aunque éste sea superior al conocer personal, no es ningún conocer. De modo que a Spaemann parece faltarle una adecuada teoría del conocimiento para hacerse cargo de la índole de la persona humana.

69 El perfil filosófico general de R. Spaemann es fundamentalmente ético. Pero intentar explicar al ser de la persona desde el punto de vista ético, el cual está centrado en el tener y en el obrar, es reductivo. Cfr. para una fundamentación acerca de que la antropología trascendental es superior a la ética mi trabajo: "La distinción entre la antropología y la ética", Studia Poliana, 13 (2011), pp. 119-153.

70 Spaemann, R., Personas, ed. cit., p. 171.

71 "El saber que le hacer saber que es precede a su conocimiento acerca de quién es y dónde está". Ibid., p. 31.

72 Cfr. Ibid., p. 35.

73 Ibid. p. 57. Más adelante escribe: "el verdadero amor no se dirige a esas cualidades (de la perso-na), sino al otro, a su identidad numérica, también cuando cambia... Sólo ama, ciertamente, aquel que no puede dar 'razones' de su amor que se hallen en las cualidades concretas del amado". Ibid., p. 88.

74 En efecto, tal hipótesis, por sostener que inicialmente no nos conocemos y que, llegamos a conocernos tras la supuesta vuelta reflexiva, equivale a defender que se llega al conocimiento propio por medio de la ignorancia, es decir, que el conocer personal surge del no conocer, lo cual es absurdo. Como es claro, esta tesis es moderna, pues defiende la prioridad -en el tiempo y en importancia- de la potencia respecto del acto, y entiende al acto como resultado del desencadenamiento espontáneo de la potencia. Es obvio, asimismo, que tal supuesto es contrario a la tesis clásica (aristotélica) de que el acto es previo, superior y condición de posibilidad de la progresiva activación de las potencias.

75 Ibid., p. 103. 
En efecto, esa oscilación se encuentra en otras de sus propuestas gnoseológicas. Así, acierta Spaemann al sentar que el intento materialista (Rorty, por ejemplo) de reducir lo mental a lo neurológico no pasa de ser un postulado injustificable. Frente a este monismo materialista defiende la distinción entre "estados psíquicos y actos intencionales" 76 , y recuerda que en el hombre lo intencional, precisamente por serlo, en modo alguno es material $^{77}$. Es claro que lo intencional en nosotros no es material. Sin embargo, hay que tener en cuenta que lo intencional en el conocer humano no son los actos (los actos intencionales son los propios de la voluntad), sino los objetos conocidos, los cuales son enteramente remitentes a la realidad ${ }^{78}$. No obstante, a pesar de estas faltas de precisión gnoseológicas, el autor ofrece otros aciertos en este punto. En efecto, por una parte, afirma que la persona dispone de pluralidad de actos y que es irreductible a ellos ${ }^{79}$; otras veces señala que la persona no se reduce a sus roles, aunque no se dé sin ellos ${ }^{80}$. Por otra parte, indica que la persona no se puede conocer a sí misma con tales actos ${ }^{81}$.

\section{Otros posibles métodos noéticos de acceso a la persona}

Otras posibilidades que Spaemann sugiere para el propio conocimiento son, por un lado, que nuestra propia verdad es manifestada por Dios ${ }^{82}$. En otra obra suya nos indica que incluso el consideraros personas depende de Dios ${ }^{83}$. Por otro lado, Spaemann mantiene que nos podemos conocer como personas a través del arrepentimiento ${ }^{84}$. Con todo, en ambas propuestas, la iniciativa es divina y el conocimiento derivado es de índole sobrenatural, es decir, no debido a la índole natural del hombre, lo cual deja pendiente la cuestión de si la persona humana dispone de un conocer natural para ir desvelando su propio sentido.

Otro posible camino es, según apunta Spaemann, el del lenguaje simbólico y metafórico. Pero el pensador alemán sabe que éste, como todo otro lenguaje, manifiesta algo a la par que oculta algo otro ${ }^{85}$. Además, es claro que todo lenguaje es sensible, por lo que difí-

76 Ibid. p. 69. La expresión actos intencionales es reiterativa en esta obra.

77 "La intencionalidad no se puede describir adecuadamente como estado físico". Ibid. p. 69. "Lo intencional no es algo psíquico, sino intelectual". Ibid. "La intencionalidad no es algo "psíquico', pero lo psíquico es algo potencialmente intelectual". Ibid., p. 71.

78 Con todo, pertenece a la tradición alemana de la filosofía contemporánea (Brentano, Husserl, Heidegger, etc.) interpretar los actos de conocer como intencionales. Sin embargo, si estos lo fueran, los objetos o ideas conocidos no podrían ser intencionales y estarían de más.

$79 C f r$. Ibid., p. 75, p. 77. En un pasaje Spaemann afirma: "la subjetividad no puede ser pensada exclusivamente como un momento estructural de actos intencionales, sino como independiente frente a ellos". Ibid., p. 111.

80 "Las personas no son roles, pero sólo son lo que son interpretando alguno, es decir, estilizándose de algún modo". Ibid., p. 96.

81 Cfr. Ibid., pp. 81-82.

82 "Únicamente a verdad absoluta revela al hombre... la verdad sobre sí mismo". Ibid., p. 96.

83 "Si Dios existe podemos ser aquello que no podemos menos que considerarnos: personas". SpaemanN, R., El rumor inmortal, ed. cit., p. 35.

84 "El desengaño a través... del arrepentimiento, conduce a uno a sí mismo". Spaemann, R., Personas, ed. cit., p. 96.

85 Cfr. Ibid., pp. 99-100. 
cilmente se puede hacer cargo de lo que no es de esa índole y, por ende, de lo que supera lo sensible: la persona.

Por otra parte, Spaemann sostiene que la persona que somos consiste en ma-nifestación a través de la naturaleza, tanto a sí mismo como a los demás: “a los demás nos manifestamos como personas gracias a aquello por lo que nos manifestamos como personas a nosotros mismos, o sea, gracias a una "naturaleza"" 86 . Con todo, si bien es verdad que, de ordinario, conocemos en parte el sentido personal de los demás a través de su naturaleza humana, el propio conocimiento personal de la intimidad no se alcanza gracias a nuestra naturaleza humana, sino directamente, es decir, sin bajar del nivel personal. Es claro que si el conocimiento personal no se diese precisamente a ese nivel, la persona humana no se podría conocer como tal por mucha mediación que hubiese de su naturaleza humana o de las ajenas. En suma, la clave del conocimiento personal no radica en su manifestación externa, sino en que tal conocer está a nivel personal. Por su parte, la clave del ser personal no radica en su manifestación natural externa, sino en su apertura interna y su vinculación íntima con otras personas, en especial, con la que le puede revelar enteramente su sentido.

Por lo demás, Spaemann indica que "el ser personal se da solamente en el acto de reconocimiento"87; que "el reconocimiento de la identidad es siempre un acto de libertad" cual es verdad, pues sin libertad no cabe ni conocer ni amor o aceptación personales a los demás; y que "en realidad el propio ser personal no se nos da antes que el de los demás" lo cual es asimismo correcto, puesto que el ser personal es apertura personal, relación. Añade que tal reconocimiento no es un deber, sino superior a los deberes, lo cual es también certero, porque el reconocer a una persona como tal no es ético -ámbito del deber-, sino antropológico - plano de la libertad personal-.

En cuanto a la libertad, Spaemann la explica primero en sintonía con la tradición filosófica griega y medieval, a saber, como libre albedrío o dominio sobre nuestros propios $\operatorname{actos}^{90}$, ciñéndola a la voluntad ${ }^{91}$. Por eso la atribuye a la persona humana en la medida en que ésta rige su naturaleza, es decir, la entiende como dominio de lo superior respecto

86 Ibid., p. 105.

87 Ibid., p. 178. Y más adelante: "sólo reconociendo a las personas nos realizamos nosotros mismos como personas". Ibid., p. 218. En otra obra mantiene tesis análoga: "las personas tienen la pretensión de ser realmente reconocidas por las demás en un sentido metafísico". Spaemann, R., El rumor inmortal, ed. cit., p. 46.

88 Spaemann, R., Personas, ed. cit., p. 177.

89 Ibid., p. 178.

90 "La idea de persona y la de libertad están estrechamente unidas. Dicho con más precisión: el concepto de persona da una nueva dimensión al de libertad cuya legitimidad ha sido negada repetidamente, a saber, la dimensión del 'libre albedrío"'. Ibid., p. 191.

91 Cfr. Ibid., p. 200 y p. 205. Pero si la libertad estuviese ceñida a la voluntad, es claro que inicialmente no existiría, porque la voluntad nativamente es una potencia pasiva. Y si luego aparece en ella la libertad, y se supone que ésta es una perfección, hay que dar cuenta de cómo educir lo perfecto de lo nativamente imperfecto, por aquello de que nadie puede dar aquello que no tiene.

92 "Sólo pueden ser libres o esclavos aquellos seres que poseen una naturaleza". Ibid., p. 192. "Ésta capacidad resulta de la propiedad de la persona de entrar en relación con su propia naturale-za, con su propio modo de ser, una relación a la que hemos definido como "tener"'. Ibid., p. 193. Pero no; la libertad humana llega en el tener porque previamente radica en el ser. 
de lo inferior ${ }^{92}$. Y también por eso, sobre el adagio medieval operari sequitur esse, llega a preguntarse: "pero, ¿no ocurre lo contrario en las personas? ¿No repercute su acción en lo que son?"93, lo que, en el fondo, equivale a preguntar: ¿acaso no es la ética superior a la antropología? Sin embargo, la precedente concepción de la libertad es reductiva ${ }^{94}$, pues la libertad manifestativa en el hombre es liberum arbitrium porque previamente es íntima, personal, trascendental. De otro modo: la libertad llega a las potencias humanas (con hábitos a la inteligencia y virtudes a la voluntad conformando lo que Spaemann denomina "segunda naturaleza") porque previamente existe en el acto de ser personal, y como el ser personal humano está constitutivamente abierto a lo superior a él, es en esa apertura en la que hay descubrir el quid de la libertad.

Con todo, Spaemann añade que "la pregunta sobre la libertad, en el sentido radical de autodeterminación, se plantea cuando al decidir hacer u omitir esta o aquella acción, decidimos también quiénes somos y qué "queremos en el fondo""95, lo cual denota que admite en nosotros la existencia de unos actos, superiores a los actos de elección o decisiones, actos que deciden sobre el sentido de la vida y que "no tienen el carácter de actos de la voluntad". Spaemann los caracteriza como actitudes de amor u odio. Pues bien, esto último que parece una en él una metaética, es sencillamente adentrarse en la antropología de la intimidad, y en esto acierta de pleno, porque "el amor no es expresión de la 'naturaleza racional' del hombre, sino de su carácter personal"96. Por eso acaba afirmado que 'la libertad que aquí suponemos no es "libre albedrío", con lo que no se pliega al paradigma griego y medieval. 'Tampoco -añade- se puede entender como autono-mía', con lo que critica el modelo kantiano.

La formula más bien como "libertad de algo. ¿De qué es libre la persona? Es libre de su propia naturaleza. La persona tiene su naturaleza, no la $e s "{ }^{\prime 97}$. Como se puede apreciar, su tesis de fondo, la de la distinción real entre persona y naturaleza, que es correcta, la usa para exponer las diversas dimensiones humanas, también la libertad. Con todo, el dirigir siempre la mirada de la persona hacia su naturaleza conlleva un inconveniente: no explicar la persona a su nivel y por correlación con lo superior a ella, sino en orden a lo menor, y esto no es suficiente.

93 Ibid., p. 198.

94 Cfr. Para la comprensión de esta tesis, vid. Polo, L., Persona y libertad, Eunsa, Pamplona, 2007.

95 Spaemann, R., Personas, ed. cit., p. 205.

96 Ibid., p. 206. A lo que añade: "esta apertura precede a todos los actos de la voluntad. No tiene el carácter del querer, sino que califica esencialmente el ser de la persona del que procede todo querer". Ibid. En efecto, "el amor precede a toda voluntad" (ibid., p. 207), porque no es de la voluntad, potencia de la esencia humana, sino del acto de ser personal.

97 Ibid., p. 207. 


\section{Conclusiones}

La antropología de R. Spaemann, sintetizada y enumerada a modo de sucintas tesis, se puede formular del modo que sigue:

1) La persona es distinta realmente de su naturaleza.

2) La persona es un descubrimiento cristiano (no siempre bien interpretado).

3) La persona indica relación personal y está abierta a la trascendencia divina.

4) El tener naturaleza es el ser de la persona.

5) La persona es temporal.

6) La persona es fin en sí.

7) La persona se conoce por reflexión y aceptación.

8) La persona se conoce por manifestación divina, por medio del arrepentimiento y del símbolo.

9) Las personas sólo se conocen por su manifestación a través de la naturaleza.

El planteamiento de fondo de la antropología de Spaemann -tesis $\mathrm{n}^{\mathrm{o}} 1$ - es correcto. Con respecto a las restantes tesis, si las agrupamos en dos órdenes, uno temático y otro metódico o gnoseológico, las cinco siguientes pertenecen al primer grupo, mientras que las tres últimas corresponden al segundo. Para concluir, conviene indicar que, a nuestro juicio, la $2^{\mathrm{a}}$ y $3^{\mathrm{a}}$ son asimismo correctas. En cambio, no lo es, por las razones aducidas, la $4^{\mathrm{a}}$. Por lo que se refiere a la $5^{\mathrm{a}}$, su examen sería de largo recorrido. No nos parece correcta, en cambio, la $6^{\text {a }}$, y esto por lo ya indicado. Por lo que respecta a las tesis del segundo grupo $-7^{\mathrm{a}}, 8^{\mathrm{a}}$ y $9^{\mathrm{a}}$ - las tres son rectificables porque incluyen carencias noéticas o de método cognoscitivo para acceder al acto de ser personal. Como consecuencia de esto segundo, su exposición y desarrollo de los temas antropológicos estudiados en el primer grupo de tesis da menos fruto que el esperado.

Los empiristas británicos modernos (y los actuales) - a los que Sapemann corrige- no admiten el yo, porque éste no cae bajo el dominio de las sensaciones. Por su parte -como denuncia Spaemann- Kant no logró despejar la X del sujeto en su ecuación antropológica $^{98}$ (tampoco Descartes, Dilthey, Heidegger, etc.), aunque a pesar de eso el pensador de Königsberg designó al hombre como fin en sí. Pero Spaemann, que parte del correcto planteamiento de la distinción real entre persona y naturaleza en el hombre, y que -como Kant- sigue llamando al sujeto fin en sí, no acaba de dar con el método noético adecuado de acceso a la intimidad personal.

98 “(En Kant) el estatuto teórico de la Antropología y su lugar sistemático quedan sin aclaración. La dificultad fundamental comienza ya con el hecho de que no está claro qué quiere saber quien pregunta '¿qué es el hombre?"'. Spaemann, R., Lo natural y lo racional, ed. cit., p. 17. Kant no logró conocer al sujeto porque "si los sujetos se convierten en objetos de la experiencia de sí mismos y de otros, pierden eo ipso lo que les hace sujetos". Ibid., p. 45. Tampoco Wittgenstein, porque el sujeto, para él, pertenece a lo que no se puede decir. Más allá del mutismo, algunos postmodernos como Derrida han negado la existencia del sujeto. 
El problema antropológico de los empiristas se puede resolver notando que el conocer sensible no es ni el único ni el superior nivel cognoscitivo natural humano; el de Descartes, Kant, Dilthey, Heidegger, etc., y asimismo el de Spaemann, indicando que la razón no es ni el único ni el superior nivel de conocimiento humano natural, pues la razón ni es persona ni puede conocer a la persona como tal, ya que carece de la vida personal: en rigor una potencia de la esencia humana no puede dar cuenta de un acto superior a ella, máxime si es el acto de ser personal humano ${ }^{99}$. Pero la persona dispone de un conocer a su altura para conocerse en buena medida y, además, como ella es conocer, al abrirse cognoscitivamente a otra persona que pueda manifestarle su sentido, puede conocer en aquélla su sentido personal. Para dar cuenta de esto, deberíamos recuperar, por encima del racional, el conocer al que la tradición medieval llamó intelectual, el cual admite dos órdenes: a) el de los hábitos innatos, sólo uno de los cuales accede al acto de ser personal y b) el del conocer como acto de ser. Pero estos órdenes noéticos ni siquiera son mencionados en las obras antropológicas de Spaemann.*

\section{Bibliografía}

Castilla, B., "En torno a la díada trascendental”, Anuario Filosófico, XXIX/2 (1996), pp. 397-414.

, Persona femenina, persona masculina, Rialp, Madrid, 1996.

Forment, E., Ser persona, U. de Barcelona, Barcelona, 1983.

GonzÁlez, A. M., Naturaleza y dignidad, Eunsa, Pamplona, 1996.

Gracián, G., El Criticón, Cátedra, Madrid, 1980.

Lombo, J. A., La persona en Tomás de Aquino, Apollinare Studi, Roma, 2001.

Marcel, G., Être et avoir, Philosophie européenne, Aubier-Montaigne, Paris, 1991.

Martínez Poncell, J., Metafísica de la persona, PPU, Barcelona, 1992.

Palacios, L. E., El concepto de persona, Rialp, Madrid, 1989.

99 Spaemann entrevé que la razón no puede dar cuenta de la persona cuando escribe que "el reconocimiento de la persona como 'alguien' no es una conclusión analógica”. Spaemann, R., Personas, ed. cit., p. 178. Pero no advierte otro método de acceso al ser personal; es más, niega que exista: "tampoco hay un acceso privilegiado al propio ser personal". Ibid. Con todo, advierte que la persona es superior a su razón: "frente a la dimensión de la razón, se descubre una dimensión todavía más profunda: la de la persona”. Ibid., p. 183.

*Artículo recibido: 27 de mayo de 2013. Aceptado: 3 de agosto de 2013. 
JuAn Fernando Sellés

Polo, L., Antropología trascendental, I-II, Eunsa, Pamplona, 2000-2003.

, La originalidad de la concepción cristiana de la existencia, Eunsa, Pamplona, $2^{\mathrm{a}}$ ed., 2012.

, Persona y libertad, Eunsa, Pamplona, 2007.

Ruiz Retegui, A., "La sexualidad humana”, Deontología biológica, Universidad de Navarra, Pamplona, 1987.

San Juan Damasceno, De fide ortodoxa.

SEllés, J. F., Antropología para inconformes, Rialp, Madrid, 3ª ed., 2012.

--------------, “La aporía de las antropologías 'totalizantes' como pregunta a los teólogos”, Salmanticenses, LVII/2 (2010), pp. 273-297.

--------------, “La distinción entre la Antropología y la Ética”, Studia Poliana, 13 (2011), pp. 119-153.

Spaemann, R., Personas. Acerca de la distinción entre 'algo' y 'alguien', Eunsa, Pamplona, 2000.

--------------, Lo natural y lo racional, Instituto de Estudios de la Sociedad, Santiago de Chile, 2011.

, El rumor inmortal, Rialp, Madrid, 2010.

, Felicidad y benevolencia, Rialp, Madrid, 1989.

Tomás De Aquino, SAnto, S. Theol.

YePEs, R., Fundamentos de antropología, Eunsa, Pamplona, 1996.

ZuBIRI, X., Sobre el sentimiento y la volición, Alianza, Madrid, 1992. 